\title{
Recruitment Strategies for Broadening Participation Programs in STEM
}

\author{
Lawrence O. Flowers, Ph.D. \\ Livingstone College \\ 701 West Monroe Street \\ Salisbury, NC 28144 - United States
}

\begin{abstract}
Increasing the diversity of the science, technology, engineering, and mathematics (STEM) workforce has been an elusive national goal for many years. A potential solution to better prepare underrepresented students for science and engineering careers are broadening participation programs. Broadening participation programs in STEM are designed to improve students' education and professional outcomes. Broadening participation programs have produced several decades of promising data that highlight the utility of these initiatives to generate positive academic and occupational outcomes for underserved students. Effective recruitment techniques that result in the attainment of program enrollment goals are paramount. Despite the importance of participant recruitment to a program's success, there are very few scholarly publications that address the issue of recruitment techniques designed to satisfy enrollment aims. Technological advances in the last twenty years have significantly improved worldwide communications. A variety of promising communication tools have afforded broadening participation program directors more opportunities to market their program and recruit participants from around the world. This article focuses on applicable traditional and online STEM program recruitment tactics that have shown to yield positive results in student enrollment. This article also calls for the increase in statistically robust research studies that seek to determine the effect of a specific recruitment strategy on recruitment goal attainment with respect to gender, ethnicity, geography, and educational level.
\end{abstract}

Keywords: recruitment, workforce, broadening participation, STEM, online

\section{Introduction}

There is an extensive body of literature that documents the importance of broadening participation programs in STEM (Carpi, Ronan, Falconer, \& Lents, 2017; Cooper, Jabanoski, \& Kaplan, 2019; Harsh, Maltese, \& Tai, 2012). There have been countless STEM-based programs targeted to underrepresented groups over the last several decades (Adedokun, Bessenbacher, Parker, Kirkham, \& Burgess, 2013; Maton et al., 2016; Vincent-Ruz, Grabowski, \& Schunn, 2018). The Meyerhoff Scholars Program is a broadening participation program that has achieved success in increasing the numbers of minority STEM PhDs. The Meyerhoff Scholars Program includes various components such as a summer transition program, mentoring, financial support, and summer research experiences (Lee \& Harmon, 2013; Maton, Pollard, Weise, \& Hrabowski, 2012). While these programs have different goals, objectives, and assessment/evaluation mechanisms, most STEM programs have a singular mission to increase the numbers of minorities in STEM education and careers. Despite the challenges faced by STEM intervention programs such as deteriorating funding and post-award decline in institutional support (Rincon \& George-Jackson, 2016), STEM-based programs designed to increase diversity in STEM education and careers have for the most part been successful at the moving needle in terms of retention, academic success, and graduation rates for underrepresented minorities.

Recruitment is one of the most important aspects of any broadening participation program in STEM. As many program directors know all too well, a major problem with broadening participation programs are the lack of student participation. While funding has increased in support of STEM intervention programs many programs are often poorly enrolled. Low recruitment in minority-based programs may eventually lead to the loss of future funding which could affect resource acquisition and the quality to fund basic program operations.

To be clear, this article is not a research article. The purpose of this article is to present proven recruitment strategies for STEM broadening participation program directors and staff. The recruitment strategies recommended in this article have been used successfully to recruit student for a career development intervention program, Advancing Interest and Motivation (AIM) for STEM Careers. AIM for STEM Careers was designed for underserved undergraduate students majoring in science, technology, engineering, and mathematics majors. 
Programmatic sessions consisted of resume and cover letter writing skills, interviewing skills, electronic job search skills, elevator talk skills, and social media job marketing tips. Each week guest speakers presented helpful information to our participants to help them to gain entry-level employment in their field of interest (SOURCE).

There are very little research articles that examined correlation between methods and compliance to program objectives. However, one study serves as a starting point for future studies regarding recruitment. Shadding et al. (2016) demonstrated the effectiveness of low-cost versus high-cost recruitment mechanism. This study aimed to establish a connection between recruitment techniques and specific academic and professional outcomes. The results indicate that low-cost recruitment methods are equally as effective in recruiting students to a summer program. Many more robust research needs to be performed to a variety of different levels to examine recruitment issues in broadening participation programs. Both quantitative and qualitative studies are needed not only to generate best practices, but also to determine the extent to which one strategy is preferred over another strategy. Institutional review board (IRB) and consent form procedures are required even when recruitment of students is fairly straightforward; for example when program participants and/or research study participants consist of students enrolled in a STEM course and are not actively recruited, yet participate in the activity phase and data collection phase.

\section{Recruitment Strategies}

A common thread of each broadening participation program grant proposal is a section that carefully illuminates a detailed recruitment plan that specifies strategies, timeline, and personnel responsible for each stage of the recruitment process. The recruitment plan must also contain measurement and statistical analysis procedures that will be performed to ensure a successful recruitment phase. The use of both an internal and external evaluator to assess recruitment efforts will lead to more accurate data. Another obvious advantage of accurately assessing recruitment is that it may lead to strategies to improve student enrollment.

Recruitment methods in this article can be organized into two main types: electronic and non-electronic. Electronic methods in this article are defined as recruitment methods that involve an online component and other technology such as a website, software, communication device (e.g., cell phone, tablet, computer, and mobile applications). Non-electric recruitments are classified a more traditional approaches to disseminating enrollment information such as through posters, presentations, telephone calls, and standard mail.

\section{Electronic Recruitment Methods}

In the current technological climate, electronic or online recruitment methods are the most preferred approaches because of they are cost effective, ubiquitous, and have been shown to more effectively align to students' interests. Since most students have a cell phone, methods that utilize cell-phone based delivery are particularly effective. Including weekly and monthly notifications can easily be sent to potential students. Studies have repeatedly shown that undergraduate students spend a considerable amount of time online and social media platforms (SOURCE). As shown in Table 1, the use of program websites, social media, electronic mailing list, text messages, YouTube, e-vites, and online polling. Online recruitment strategies are cost effective because many of the web-based methods are free or cost very little.

Developing a website for your broadening participation program is an excellent idea. Not only does it allow you to market your program and permit uncensored dissemination of your program's mission, objectives, and experimentallyderived research findings but it also creates and opportunity to allow potential participants to apply to your program by completing an online application.

The inclusion of an electronic notification feature on the website will keep applicants informed on the status of the acceptance process and facilitate communication between applicant and program staff. Inserting online applications on your project website will streamline the enrollment process for your participants and ultimately improve your enrollment numbers. Adding recruitment links to your program's social media pages on Facebook, Twitter, and Instagram will provide another opportunity to expose students to your programmatic content as well as means to recruit participants.

Another online recruitment approach could be to implement a webinar in which program staff or program directors would present the purpose, expectations, and objective of the programs. Free webinar platforms such as Zoom and that you can use that contain an adequate and sufficient number of features necessary to present a webinar. Also during this brief webinar dissemination of program application opportunities are shared. More importantly, during this webinar potential applicants are able to ask questions to actual program staff. Using Blackboard or other free content management systems such as Moodle confer an opportunity for program directors to use these platforms to recruit students and market the program to potential participants. 


\section{Table 1 - Recruitment Strategies for Broadening Participation Programs}

\section{Electronic Methods}

websites, e-vites, text messages, notifications, social media, mobile applications, e-mail, content management systems (e.g., Blackboard), webinar, web conferencing, video conferencing, TV commercial, YouTube video, digital signage systems

\section{Non-Electronic Methods}

posters, newsletters, radio station, newspapers, presentations, standard mail, telephone, banners, current and former program participants, brochures

\section{Non-Electronic Recruitment Methods}

Non-electronic methods represent more traditional forms of communication. While electronic methods have the potential of reaching a larger audience at a faster rate, non-electronic methods are nonetheless effective and should be utilized.

Create visually-appealing recruitment posters and place those posters in highly visible locations such as the cafeteria, dormitory, bookstore, athletic facility, classrooms, STEM buildings, library, auditorium, computer lab. Recruitment posters must succinctly address the basic questions who, what, when, where, and how. These posters can be designed in-house or designed by a graphic designer at a low cost. In short recruitment posters must convey important information that interested students can use to learn about your broadening participation program and apply to your program. Recruitment presentations are another excellent method to recruitment students in your program. Using this strategy a member of your staff can introduce your program to potential applicants in STEM courses, campus/community programs, and campus/community activities. During the recruitment presentations your program representative should allow time for interested students to apply for your program. Additionally, during the recruitment event it is advisable to collect contact information from the audience for future dialogue opportunities. Using regional and national organizations to market your program is an effective approach to reach thousands of potential participants. Contacting Greek organizations to assist in disseminating information about your program will improve enrollment numbers by specifically targeting minority students. The use of radio stations on your campus or external locations to promote your program is also an excellent recruitment method. The use of standard mail is also an effective method of reaching potential program participants.

Anytime you include human subject component in a program or research project. There is an opportunity for bias in the recruitment process. Unless you are performing a randomized controlled trial, then bias is something that may occur in the recruitment process. Oftentimes bias in the recruitment process is inherently connected to the eligibility requirements. For example, if you require students to have a 3.3 GPA in order to participate in your program then you are essentially targeting students with good study skills. Ultimately, remember that the best recruitment emissaries for your program are previous and former participants. Implementing a program that truly benefits students will produce program alumni who aid in recruitment efforts.

\section{Evaluation of Recruitment Strategies}

A helpful technique to evaluate recruitment outcomes is to survey undergraduate and graduate students either in your existing program or on your campus. Survey questions should be designed to find out from a student perspective what approaches they found the most helpful. While different survey participants will give mixed responses, this exercise will ultimately expand recruitment strategies for your program.

During the evaluation phase, it is a good idea to ask your participants to inform you of the method or methods that were the most effective in terms of their recruitment. Another question could explore which methods the students find the least effective. A third question could seek to determine the rationale for selecting their most effective and least effective method of recruitment. The third question is very important because what you will find that students find multiple methods to be potentially beneficial. Indeed, effective recruitment strategies involve a collection of techniques to reach enrollment goals. The most effective method would be the method that essentially was the major catalyst that convinced the student to submit an application for consideration in your program. 
Setting enrollment objectives is essential. Due to normal student attrition it is always prudent to set a higher recruitment goal than needed to deal with reduction in the number of students who apply and the number of students who accept an offer to join the program. When recruiting for a research study participants be mindful that based on institutional review board policy, students can withdraw their participation at any time. It is a good idea to set both formative and summative recruitment goals. Formative recruitment numbers are participant numbers that are assessed at the midway point of a specified program application due date. Summative recruitment numbers are the participation application. Obviously, during the formative analysis period if the numbers are not at least $50 \%$ of the target goal, then additional recruitment strategies must be employed in order to reach our goals. Also, as a program director, during the summative recruitment analysis if your recruitment goals are not met do not hesitate to extend the due date to achieve the enrollment numbers you desire. Furthermore, be sure to add recruitment costs to your budget. While recruitment can be inexpensive, funds devoted specifically to recruitment costs will allow for elaborate and potentially beneficial recruitment outcomes. The development of a rubric for recruitment strategies is important. To my knowledge, I have not seen a rubric for recruitment strategies.

\section{Conclusion}

Program recruitment is one of the most critical aspects of program sustainability. Oftentimes recruitment procedures are designed as an afterthought and be involve multiple members of the project staff. Recruitment strategies will enhance enrollment in a specific broadening participation program. Obviously, modifications must be made to the proposed strategies when your target population is in-state compared to out-of-state, national versus international, intrainstitutional versus inter-institutional, or on-campus versus commuter students. As a note of caution, stay mindful that just because one recruitment method does not work for one program, it doesn't mean that the same methods will not work for another program. Understand that it is possible that certain demographics may respond differently to different stimuli. It is impossible to figure out which method will work, being consistent with the methods in this article will lead to successful results.

Incentives can be a strong motivator. Consider creating a reward structure that encourages potential participants to apply to your program. When recruiting for research study participants always include a consent form with the application. Doing this will not only save time later assuming an applicant is selected for inclusion, but will provide additional information to your applicants about the specific nation of the research project and potential hazards (if any) associated with project. Due to the purported educational and professional outcomes of SIPs, recruitment in a quality research or training program may also indirectly contribute to improved academic performance, retention rates, and graduation rates.

\section{Acknowledgments}

This work was supported by grants funded by the National Science Foundation (HRD-0811728 and HRD-1505098).

\section{References}

Adedokun, O., Bessenbacher, A., Parker, L., Kirkham, L., \& Burgess, W. (2013). Research skills and STEM undergraduate research students' aspirations for research careers: Mediating effects of research self-efficacy. Journal of Research in Science Teaching, 50, 940-951.

Carpi, A., Ronan, D., Falconer, H., \& Lents, N. (2017). Cultivating minority scientists: Undergraduate research increases self-efficacy and career ambitions for underrepresented students in STEM. Journal of Research in Science Teaching, 54, 169-194.

Cooper, J., Jabanoski, K., \& Kaplan, M. (2019). Exploring experiential opportunity impacts on undergraduate outcomes in the geosciences. Journal of Geoscience Education, 67, 249-265.

Harsh, J., Maltese, A., \& Tai, R. (2012). A perspective of gender differences in chemistry and physics undergraduate research experiences. Journal of Chemical Education, 89, 1364-1370.

Lee, D., \&. Harmon, K. (2013). The Meyerhoff Scholars Program: Changing minds, transforming a campus. Metropolitan Universities, 24, 55-70.

Maton, K., Beason, T., Godsay, S., Domingo, M., Bailey, T., Sun, S., \& Hrabowski, F. (2016). Outcomes and processes in the Meyerhoff Scholars Program: STEM PhD completion, sense of community, perceived program benefit, science identity, and research self-efficacy. CBE - Life Sciences Education, 15, 1-15. 
Maton, K., Pollard, S., Weise, T., \& Hrabowski, F. (2012). The Meyerhoff Scholars Program: A strengths-based, institution-wide approach to increasing diversity in science, technology, engineering and mathematics. Mount Sinai Journal of Medicine, 79, 610-623.

Rincon, B., George-Jackson, Casey. (2016). STEM intervention programs: Funding practices and challenges. Studies in Higher Education, 41, 429-444.

Shadding, C., Whittington, D., Wallace, L., Wandu, W., \& Wilson, R. (2016). Cost-effective recruitment strategies that attract underrepresented minority undergraduates who persist to STEM doctorates. SAGE Open, 6, 1-15.

Vincent-Ruz, P., Grabowski, J., \& Schunn, C. (2018). The impact of early participation in undergraduate research experiences on multiple measures of premed path success. Scholarship and Practice of Undergraduate Research, 1, 13-18. 